Article

\title{
Understanding Low Cycle Fatigue Behavior of Alloy 617 Base Metal and Weldments at $900{ }^{\circ} \mathrm{C}$
}

\author{
Rando Tungga Dewa ${ }^{1}$, Seon Jin Kim ${ }^{1, *}$, Woo Gon Kim ${ }^{2}$ and Eung Seon Kim ${ }^{2}$ \\ 1 Department of Mechanical Design Engineering, Pukyong National University, Busan 608-739, Korea; \\ rando.td@gmail.com \\ 2 Korea Atomic Energy Research Institute (KAERI), Daejeon 305-353, Korea; wgkim@kaeri.re.kr (W.G.K.); \\ kimes@kaeri.re.kr (E.S.K.) \\ * Correspondence: sjkim@pknu.ac.kr; Tel.: +82-51-629-6163; Fax: +82-51-629-6150
}

Academic Editor: Filippo Berto

Received: 4 July 2016; Accepted: 26 July 2016; Published: 2 August 2016

\begin{abstract}
In order to better understand the high temperature low cycle fatigue behavior of Alloy 617 weldments, this work focuses on the comparative study of the low cycle fatigue behavior of Alloy 617 base metal and weldments, made from automated gas tungsten arc welding with Alloy 617 filler wire. Low cycle fatigue tests were carried out by a series of fully reversed strain-controls (strain ratio, $R_{\varepsilon}=-1$ ), i.e., $0.6 \%, 0.9 \%, 1.2 \%$ and $1.5 \%$ at a high temperature of $900{ }^{\circ} \mathrm{C}$ and a constant strain rate of $10^{-3} / \mathrm{s}$. At all the testing conditions, the weldment specimens showed lower fatigue lives compared with the base metal due to their microstructural heterogeneities. The effect of very high temperature deformation behavior regarding cyclic stress response varied as a complex function of material property and total strain range. The Alloy 617 base weldments showed some cyclic hardening as a function of total strain range. However, the Alloy 617 base metal showed some cyclic softening induced by solute drag creep during low cycle fatigue. An analysis of the low cycle fatigue data based on a Coffin-Manson relationship was carried out. Fracture surface characterizations were performed on selected fractured specimens using standard metallographic techniques.
\end{abstract}

Keywords: Alloy 617; very high temperature gas-cooled reactor (VHTR); gas tungsten arc welding (GTAW); weldments; low cycle fatigue (LCF); fatigue life; fracture surface characterization

\section{Introduction}

The Next Generation Nuclear Plant (NGNP) being developed in the Republic of Korea is the Very High Temperature gas-cooled Reactor (VHTR). The VHTR merges the diversities of the baseline design to allow eventual operation at gas outlet temperatures up to $950{ }^{\circ} \mathrm{C}$. In the VHTR, some of the major components such as the reactor internals, the reactor pressure vessel, the piping, the hot gas ducts (HGD), and the intermediate heat exchangers (IHX) are classified as key components, with helium as a primary and secondary coolant. The IHX performs the main purpose in the operation of the NGNP, transferring heat from the primary reactor helium to an active working fluid at a lower temperature. Leading materials of potential concern include nickel-base Alloy $800 \mathrm{H}$, Alloy 617, Alloy 230, and Hastelloy X for the high temperature components. In the high temperature design, creep and fatigue resistance, oxidation resistance, and phase stability need to be satisfied $[1,2]$. Alloy 617, a nickel-base super alloy, is a leading candidate material for a VHTR because of its excellent high-temperature mechanical properties, formability, and weldability. Alloy 617 is strengthened by solid solution hardening precipitates provided by the alloy chemical compositions of chromium, cobalt, and molybdenum, which are required for high temperature strength [3]. In Alloy 617, the high temperature oxidation resistance is derived from the high nickel and chromium content. In addition, grain boundary strengthening takes place during the solidification process, with the aid of carbide 
precipitates. Primary carbides, $\mathrm{M}_{6} \mathrm{C}$, have a complex structure and they precipitate in a relatively high temperature process. A more complex secondary carbide, $\mathrm{M}_{23} \mathrm{C}_{6}$, is suspected and mainly grows along the grain boundary. These carbide precipitates are known to have a high content of chromium. They diffuse and form a depleted zone of a Cr-rich oxide layer on the outer surface, namely $\mathrm{Cr}_{2} \mathrm{O}_{3}$ [4]. Consequently, the Alloy 617 is expected to provide good thermal stability for components of power generating plants with a high temperature strength up to $950{ }^{\circ} \mathrm{C}$ [5]. The IHX have to be joined to piping or other components by welding technique. Very high temperature deformation is expected to be a predominant failure mechanism of the IHX, and thus, weldments used in its fabrication experience varying cyclic deformation and are a key element of all designs [6,7].

In an actual high temperature design evaluation, however, fatigue and creep damage are usually more critical than other design parameters. In this circumstance, the low cycle fatigue (LCF) loadings represent a predominant failure mode from the temperature gradient induced thermal strain during operation as well as in the startups and shutdowns and in power transients or with temperature change of the flowing coolant having a low loading rate [5-8]. Because of these shortcomings, significant consideration of LCF behavior is needed in the design and life assessment of such components working in high temperature conditions. The welded section material could be considerably affected by the welding process which is responsible for heterogeneities. As such, the weldments are critical considerations in the engineering design because they are the weakest links in the components and may have some original defects. Experience with nickel alloy weldments in structural applications suggests that most cases of high temperature fatigue failures occur at the weldments or in the heat affected zone (HAZ) [6]. Although Alloy 617 has many superior properties, numerous researchers have reported that the fatigue life varies widely at high temperature and it is generally found that the weldment specimens have a lower fatigue life compared to the base metal, although only limited data were available on the weldments material [5-11]. A draft Code Case was developed to qualify the Alloy 617 for nuclear service; the need for fatigue data, such as the influence of strain ranges, strain rate, and temperature at thermally induced strain rates in the IHX parent material and weldments material is necessary to predict the lifetime of the reactor components. However, the behavior of Alloy 617 weldments is not yet fully understood, and there remains a need for further experiments; a lot of data needs to be supplemented at very high temperatures due to the variability in the fatigue response of the element parts of the weldments (i.e., weld, HAZ, and base metal) to confirm the suitability of a baseline draft Code Case [6].

The aim of this work focuses on the understanding of the LCF behavior of Alloy 617 base metal and weldments, made from an automated gas tungsten arc welding (GTAW) process with Alloy 617 filler wire. LCF tests have been carried out through a series of fully reversed strain-controls (strain ratio, $R_{\varepsilon}=-1$ ) regarding to the four different total strain ranges, i.e., $0.6 \%, 0.9 \%, 1.2 \%$ and $1.5 \%$ at a high temperature of $900{ }^{\circ} \mathrm{C}$ in an air environment, in accordance with the ASTM Standard E606. The effect of very high temperature deformation behavior of Alloy 617 base metal and weldment specimens is comparatively investigated as a function of total strain range. The plastic deformation regarding stress response was reflected as damage accumulation in the structural material, and it could be correlated to the fatigue life of the material. An evaluation of LCF behavior data was performed using the well-known relationship based on a Coffin-Manson relationship, and the material constants were also determined. The LCF fracture surface microstructures were characterized on selected fractured specimens, and thus, the microstructural changes under various conditions are also reported quantitatively using standard metallographic techniques.

\section{Materials and Experiments}

A commercial grade Alloy 617 is approved for non-nuclear construction in the ASME Code. Thus the composition (wt \%) of the Alloy 617 used for material chosen in this study is $53.11 \mathrm{Ni}, 22.2 \mathrm{Cr}$, $12.3 \mathrm{Co}, 9.5 \mathrm{Mo}, 1.06 \mathrm{Al}, 0.08 \mathrm{C}, 0.949 \mathrm{Fe}, 0.4 \mathrm{Ti}, 0.084 \mathrm{Si}, 0.029 \mathrm{Mn}, 0.027 \mathrm{Cu}, 0.003 \mathrm{P},<0.002 \mathrm{~S}$, and $<0.002 \mathrm{~B}$. The initial microstructure analysis of Alloy 617 was revealed in a previous study [2,6]. Alloy 617 has 
a fully austenitic face centred cubic (fcc) structure which maintains superior mechanical properties at high temperature. The fcc matrix, known as, $\gamma$, mainly consists of nickel, cobalt, iron, chromium, and molybdenum. Figure 1 shows the microstructure of the cross-section of a weld, the HAZ, and the base region. However, the microstructure of the base metal with well-uniformed equiaxed grains is approximately $100 \mu \mathrm{m}$ in diameter. The weld region is comprised of austenitic large columnar grains with a dendritic structure due to solidification during the welding process. As such, the HAZ of the weld was formed by carbide dissolution and a small amount of grain growth. Cylindrical specimens with $6.0 \mathrm{~mm}$ in diameter in the reduced section with a parallel length of $18 \mathrm{~mm}$ and gauge length of $12 \mathrm{~mm}$ were used for the LCF test specimens. Low stress grinding and polishing were applied in the final machining to avoid the formation of notches. LCF weldment specimens were machined from weld pad in the transverse direction to the welding direction. Alloy 617 filler wire was used with a diameter of $2.4 \mathrm{~mm}$. After the welding process, the soundness of the weldments was qualified through an ultrasonic test (UT), a tensile test, and a bending test. The bending testing results coincide well with ASME specifications, which means the micro-crack is within $3.2 \mathrm{~mm}$. It was also observed that the weldments exhibited acceptable ductility. Nevertheless, the soundness of the weldments gives no indication of welding defects. The shape of the weld pad has a single V-groove with an angle of $80^{\circ}$ and $10 \mathrm{~mm}$ root gap from a $25 \mathrm{~mm}$ thick rolled plate. Figure 2 shows the shape and dimension of the weld pad configuration and the schematic of weldment specimens used in this investigation. The gauge section of the weldment specimen mainly covers the weld and HAZ materials only.

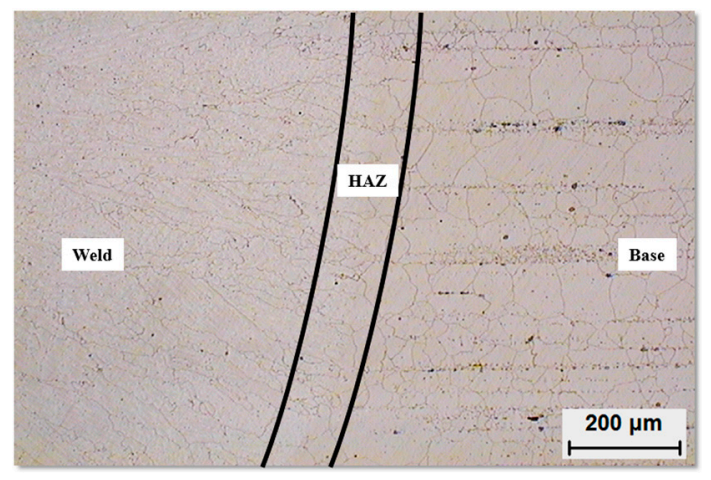

Figure 1. Microstructure of the cross-section of Weld-Heat affected zone (HAZ)-Base region.

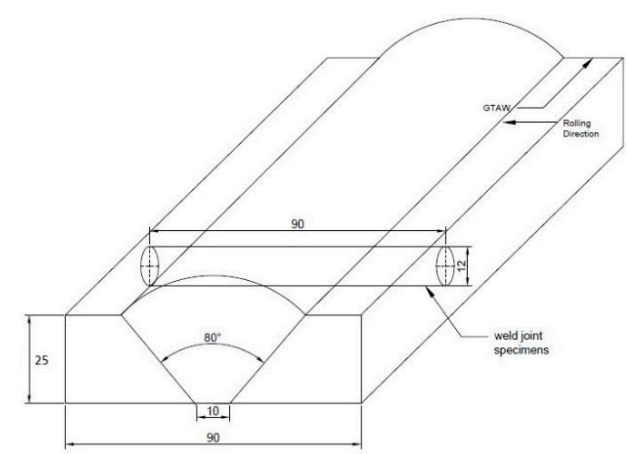

(a)

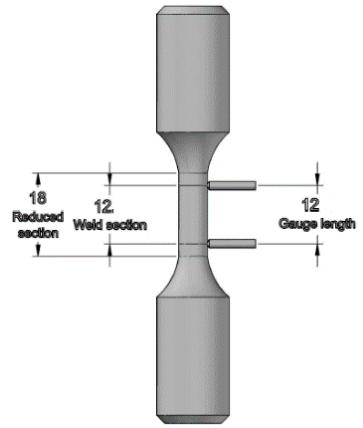

(b)

Figure 2. (a) The weld pad configuration; (b) The schematic of shape and dimension of the weldment specimen (all dimensions are in millimeters).

A closed loop $100 \mathrm{kN}$ servo hydraulic testing machine (MTS 370 Landmark, Eden Prairie, MN, USA) was used and equipped with a tube furnace for heating the specimens of Alloy 617 base metal and weldment in dry air, which ensured that the temperature remained within $\pm 2{ }^{\circ} \mathrm{C}$ of the nominal temperature throughout the test. The specimen was held at a target temperature with 
zero load for about $30 \mathrm{~min}$ to allow temperatures to stabilize before the commencement of the test. A full-scale photograph of the LCF testing apparatus is shown in Figure 3. We performed fully reversed (strain ratio, $R_{\varepsilon}=-1$ ) axial strain controlled LCF tests of Alloy 617 base metal and weldment specimens at $900{ }^{\circ} \mathrm{C}$ regarding to the four different total strain ranges, i.e., $0.6 \%, 0.9 \%, 1.2 \%$ and $1.5 \%$. A triangular waveform and a constant strain rate of $10^{-3} / \mathrm{s}$ were applied. The failure criterion was defined by the number of cycles which means a $20 \%$ reduction in the stress ratio (peak tensile over compressive stress ratio). In order to examine the LCF fracture morphologies, we characterized the post-fracture analysis of the selected specimens which split into two pieces in the preliminary observation using standard metallographic techniques. The fatigue specimens, cut around crack initiation sites, were chemical-polished with a mixed solution of ethanol, hydrochloric acid, and copper II chloride. The characterization was carried out using a scanning electron microscopy (SEM Hitach JEOL JSM 5610, JEOL Ltd., Tokyo, Japan) along with an energy dispersive X-ray (EDX, INCA Energy, Oxford Instruments Analytical, Halifax Road, UK) facility to determine the position of the crack initiation site as well as an optical microscope (OM JP/GX51, Olympus Corp., Tokyo, Japan) to provide an explanation of the LCF failure mechanism.

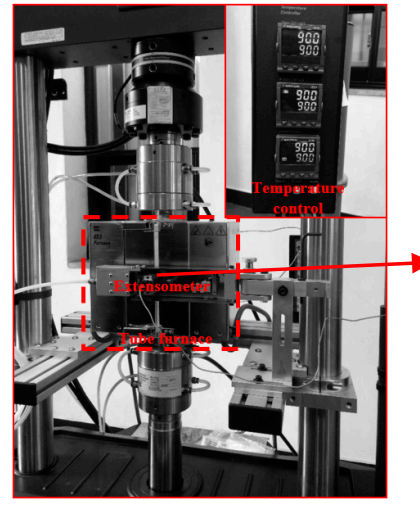

(a)

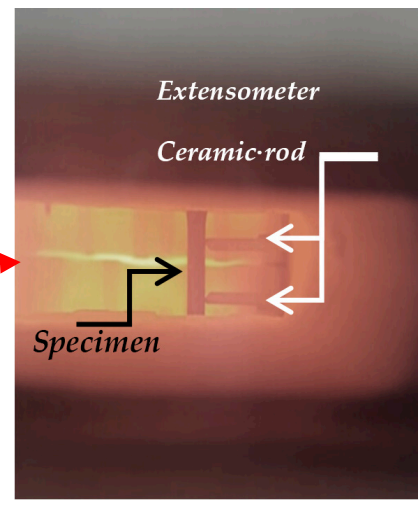

(b)

Figure 3. (a) Full-scale view of the low cycle fatigue (LCF) testing apparatus; (b) Photograph of the view port during LCF testing.

\section{Results and Analysis}

\subsection{Fatigue Life and Cyclic Stress Response Behavior}

Figure 4 shows the tensile test results of the Alloy 617 base metal and weldment specimens. Alloy 617 base metal and weldment specimens showed different characteristics of mechanical properties as microstructural differences: As revealed in the previous study [2], the hardness value of the HAZ and weldments had a higher value due to the austenitic phase with fine equiaxed dendrites. It is noticeable that the Young's modulus was similar for the Alloy 617 base metal and weldment specimens, while the strength of the weldments was higher than the base metal, but with a lower percentage of elongation. The higher strength of the weldment specimens could be attributed to the austenitic nickel-chromium morphology with a dendritic structure, and formation of precipitates of the weldments in the solidification grain boundaries [4].

At all the testing conditions, the weldment specimens showed lower fatigue lives compared with the base metal, and also the fatigue life of both base metal and weldment specimens decreased with increase in the total strain range, as shown in Figure 5. Figure 6 shows the peak tensile and compressive stresses of the cyclic stress response under four different total strain ranges during LCF testing. The peak tensile and compressive stress response were of the same magnitude, which means the strain accumulation is practically similar during cyclic deformation. The peak tensile stress, as a function of the number of cycles, attained a stable value within less than 10 cycles. The peak stress 
value of the half-life cycle increases with increasing total strain range of the weldment specimens, otherwise, the lower total strain ranges showed higher peak stresses for the base metal. These results could suggest that the reduction in fatigue life is not strongly dependent on cyclic deformation. At all the testing conditions, the cyclic stress response behavior of Alloy 617 at the high temperature of $900{ }^{\circ} \mathrm{C}$ showed a cyclic softening region for the major portion of the time in each total strain range. At the end of the test, the stress amplitude decreased rapidly at the formation of macro-crack initiation or just before fracture. Under the lowest total strain range, i.e., $0.6 \%$, saturation phase was also observed. A short period of cyclic initial hardening was observed below 10 cycles for all weldment specimens at any given total strain ranges, the saturation phase also appeared at lower total strain range, and remained in the softening phase until failure.

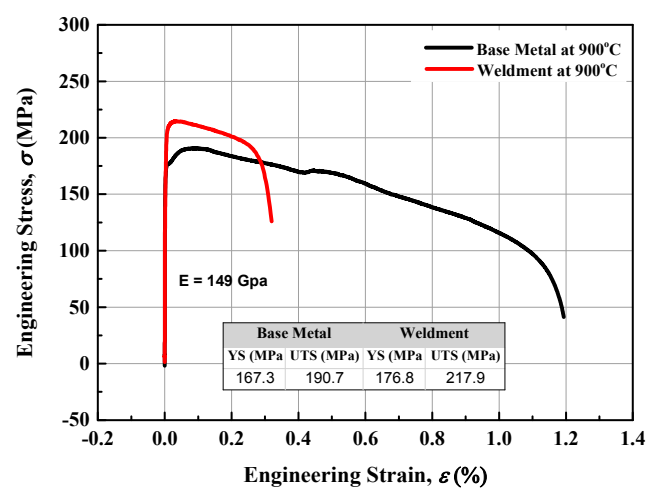

Figure 4. Tensile stress-strain curves of the Alloy 617 base metal and weldment specimens.

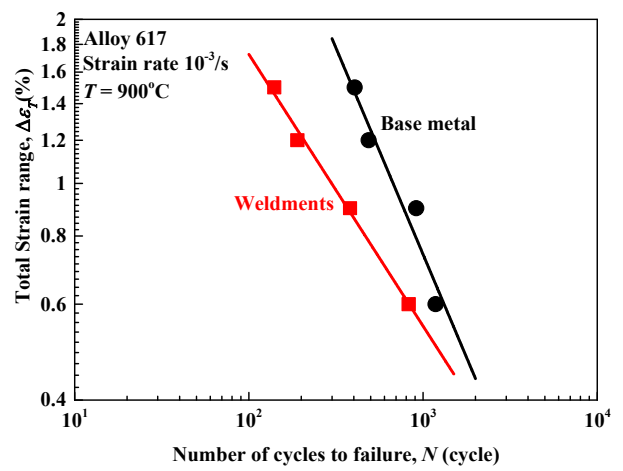

Figure 5. Comparison of low cycle fatigue resistance of Alloy 617 base metal and weldment specimens.

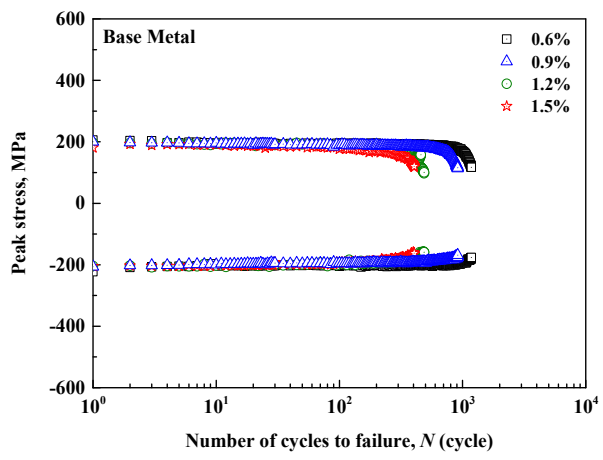

(a)

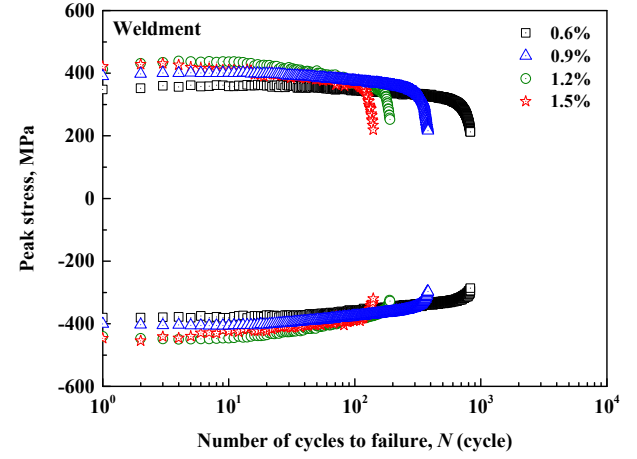

(b)

Figure 6. Peak tensile and compressive stress response of the Alloy 617: (a) base metal; (b) weldment specimen, as a function of the number of cycles. 
The cyclic stress-strain response behavior could be determined through the well-known Ramberg-Osgood relationship (Equation (1)), and also linear regressions could be taken which provide a measure to cyclic straining.

$$
\frac{\triangle \sigma}{2}=K^{\prime}\left(\frac{\triangle \varepsilon_{\mathrm{p}}}{2}\right)^{n^{\prime}}
$$

where $\Delta \sigma, \Delta \varepsilon_{\mathrm{p}}, K^{\prime}$, and $n^{\prime}$ represent the stress amplitude, the plastic strain magnitude, the cyclic strength coefficient and cyclic strain hardening, or softening exponent, respectively. Figure 7 shows the cyclic stress amplitude versus plastic strain response at half-life. The material constants, $K^{\prime}$ and $n^{\prime}$, were obtained through the cyclic stress-strain curves by the least square fit method.

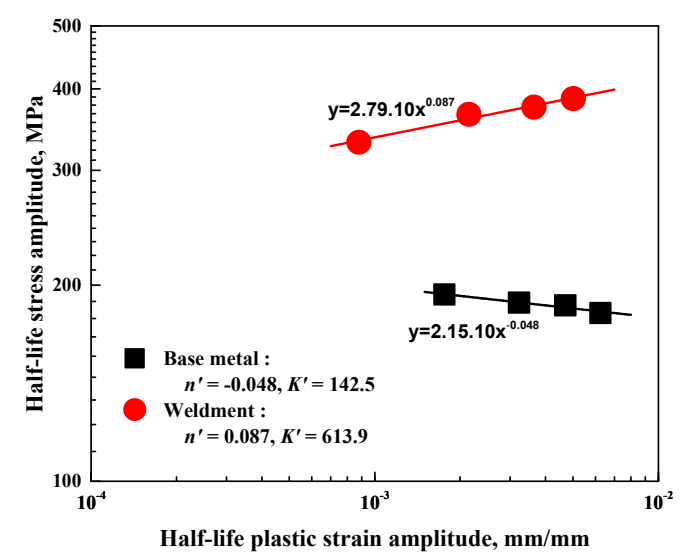

Figure 7. The cyclic stress-strain behavior of Alloy 617 base metal and weldment specimens at $900{ }^{\circ} \mathrm{C}$, determined through the Ramberg-Osgood relationship.

On the Alloy 617 weldment specimens, the plastic strain increased continuously under LCF loading as the cyclic stress amplitude at the half-life increased. Alloy 617 weldment specimens were deformed by the plastic flow mechanism and show a cyclic hardening mechanism. On the contrary, the Alloy 617 base metal, showed a decrease in cyclic stress amplitude when the total strain range was elevated, which is a definition of the cyclic softening mechanism. This finding on the base metal was similar to a literature review [8], Wright et al. confirmed that under fatigue loading at very high temperature, the Alloy 617 exhibits an exponential decrease of peak stress amplitude with increasing strain amplitude induced by the solute drag creep mechanism. These stress drops with increasing total strain ranges have been attributed to solute-drag creep. Under high total strain ranges (beyond the flow stress peak) the solute drag flow peak only occurs during the first cycle, and the lower flow stress is maintained for each cycle, after the first cycle has established enough plastic flow to reach this steady state value. Figure 8 shows that a visible pattern of stress-strain behavior is noticeable under high-temperature fatigue, featured by an initial stress drop in the first cycle. Solute drag creep occurs due to the dynamic interactions between dislocations and the solute atoms. The solutes hinder dislocation motion resulting in relatively high resistance to plastic flow, and during cyclic loading the rearrangement and annihilation of the dislocation substructures overcome the energy and begin dragging the solutes. This causes the overall dislocation density to decrease and reduces the flow stress. In the case of the Alloy 617 the base metal experiences a small total strain range, the cyclic stress response remains at the higher value. The results are in good agreement with that of the empirical rule $\left(\sigma_{\mathrm{uts}} / \sigma_{\mathrm{ys}}<1.2\right)$, in which metallic materials cyclically soften; in this study we found that $\left(\sigma_{\mathrm{uts}} / \sigma_{\mathrm{ys}}=1.13\right)$ for the base metal and $\left(\sigma_{\mathrm{uts}} / \sigma_{\mathrm{ys}}=1.23\right)$ for the weldment specimens. 


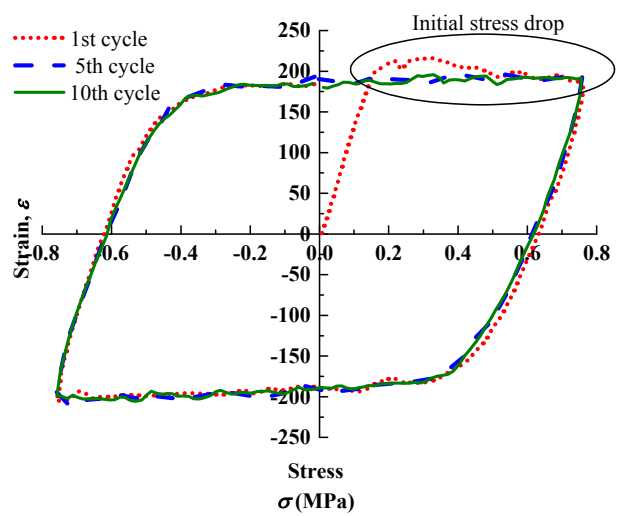

Figure 8. First, fifth, and tenth cycle of a $1.5 \%$ total strain range at $900{ }^{\circ} \mathrm{C}$, showing initial stress drop in the stress-strain curve.

\subsection{Stress-Strain Hysteresis Loops}

Figure 9 shows the stress-strain hysteresis loops of the Alloy 617 base metal and weldment specimens for cycles 1, 5, 10, stable cycle (half-life), and fractured cycle, at a selected total strain range of $0.9 \%$. The Alloy 617 base metal showed a continuous decrease in the peak stress as a function of the cycles, as shown in Figure 9a. Meanwhile, in the case of the weldment specimens as shown in Figure $9 \mathrm{~b}$, initial hardening in the peak stress was observed below 10 cycles, and continued to decrease until failure.

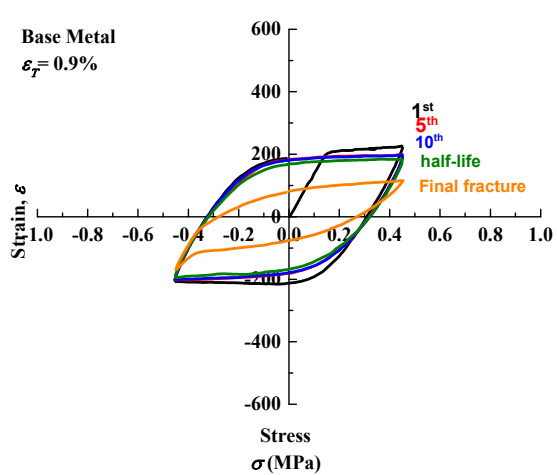

(a)

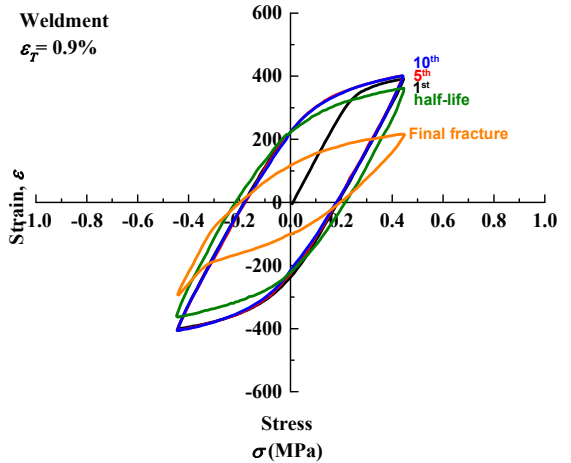

(b)

Figure 9. Stress-strain hysteresis plots of the Alloy 617: (a) base metal; (b) weldment specimens for selected cycles; total strain range of $0.9 \%$, at $900{ }^{\circ} \mathrm{C}$.

Figure 10 shows comparative stress-strain hysteresis loops for the Alloy 617 base metal and weldment specimens for the half-life cycle at each total strain range. The plastic strain accumulation (represented by the shape of the hysteresis loops) shows more significantly an increase as a function of total strain range, although, we found a relatively higher plastic strain magnitude for the base metal (Figure 10a) compared with those of the weldment specimens (Figure 10b). At each total strain range, the hysteresis loops of the weldment specimens were relatively narrower than those of the base metals. The overall cyclic stress response curve of weldment specimens is higher than that of the base metal. The inner area of the hysteresis loop represents the plastic energy per unit volume dissipated as plastic work during a cycle $\left(\mathrm{J} / \mathrm{m}^{3}\right)$, and decreases as the stress amplitude decreases. As previously described, Figure 10a shows the cyclic strain softening. From Figure 10b some cyclic strain hardening is obvious but depends on the total strain ranges. This behavior conforms well to a cyclic hardening characteristic, and is related to the accumulation of dislocation density within the matrix, $\gamma$, and the configuration of materials. As the LCF testing proceeds, the total dislocation density depends on the plastic strain 
accumulation (in accordance with the strain range), and the material resistance against the dislocation increases, while the stress amplitude continues to be slightly increasing [12].

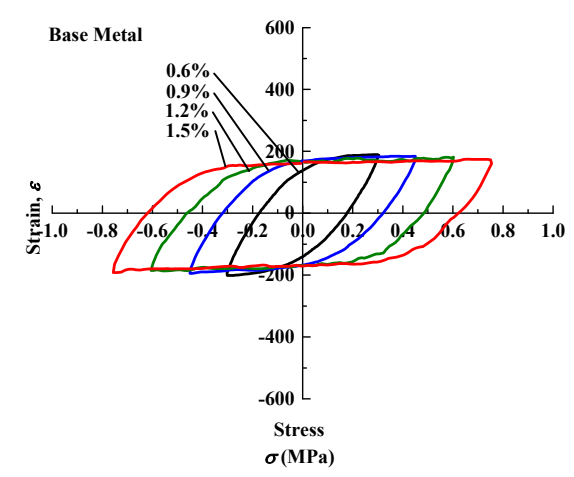

(a)

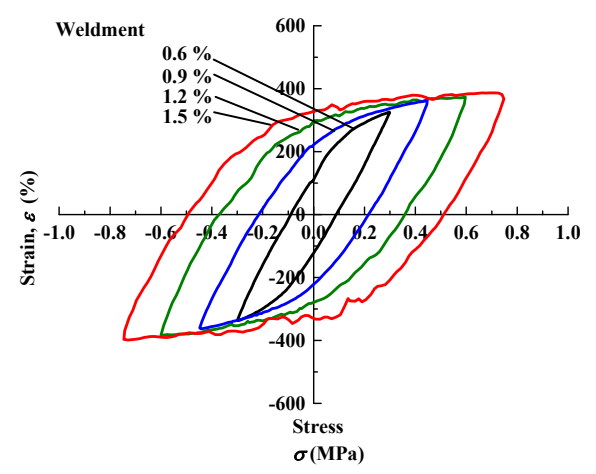

(b)

Figure 10. Comparative stress-strain hysteresis loop plots at the half-life cycle of the Alloy 617: (a) base metal; (b) weldment specimens regarding different total strain ranges at $900{ }^{\circ} \mathrm{C}$.

\subsection{Strain-Life Data Analysis}

The axial strain controlled LCF test provides crucial information on the strain-life relationship, and could be used to improve the fatigue performance. It is obvious that the LCF life is sensitive to the total strain range and the material property (namely, base metal and weldments). Therefore, the Alloy 617 base metal and weldments represent a typical Coffin-Manson life dependence on total strain range. The well-known, Coffin-Manson fatigue design method correlates the number of cycles to failure, $N_{\mathrm{f}}$, with the presented strain history of the specimen under LCF loadings. This model could be used to model the LCF problem, when the plastic strain range, $\Delta \varepsilon_{\mathrm{P}}$, is the same or even larger than the elastic strain range, $\Delta \varepsilon_{\mathrm{e}}$. The Coffin-Manson method could be worked out with the stress-strain (log scale) relationship, as well as the Ramberg-Osgood relationship, to describe the hysteresis loop, considering cyclic softening or hardening of the material. Equation (2) can be introduced:

$$
\frac{\triangle \varepsilon_{\mathrm{T}}}{2}=\frac{\triangle \varepsilon_{\mathrm{p}}}{2}+\frac{\triangle \varepsilon_{\mathrm{e}}}{2}=\frac{\sigma_{\mathrm{f}}^{\prime}}{E}\left(2 N_{\mathrm{f}}\right)^{b}+\varepsilon_{\mathrm{f}}^{\prime}\left(2 N_{\mathrm{f}}\right)^{c}
$$

where, $\Delta \varepsilon_{\mathrm{T}} / 2$ is the total strain amplitude, $\Delta \varepsilon_{\mathrm{e}} / 2$ is the elastic strain amplitude, $\Delta \varepsilon_{\mathrm{P}} / 2$ is the plastic strain amplitude, $2 N_{\mathrm{f}}$ is the number of reversals to failure, $\sigma_{\mathrm{f}}{ }^{\prime}$ is the fatigue strength coefficient, $b$ is the fatigue strength exponent, $\varepsilon_{\mathrm{f}}$ ' is the fatigue ductility coefficient, $c$ is the fatigue ductility exponent, and $E$ is the elastic modulus, respectively.

Equation (2) mathematically represents the Coffin-Manson curves of the strain amplitude and the number of reversals to failure shown in Figure 11. The results show the success of this approach through experimental testing. The material constants were calculated through Equation (2), and simply by fitting the curves using a least square fit method. The derived fatigue life coefficients in this work are also listed in Table 1. In this study, the $c$ slopes of -1.04 and -0.96 of the Alloy 617 base metal and weldments, respectively, were obtained according to the experimental data. At all total strain ranges, the base metals exhibited the plastic regime controlling the fatigue deformation. Over a large strain range, it could be seen that the plastic regime controlled the fatigue deformation, and furthermore, the small strain range was induced by a larger elastic deformation rather than plastic deformation of the weldments. The domain in the intersection between plastic and elastic strain line, is called the transition of the fatigue life, $N_{t}$. From Figure 11, we obtained $2 N_{t}$ of 3766 cycles and 628 cycles for base metal and weldment specimens, respectively. 


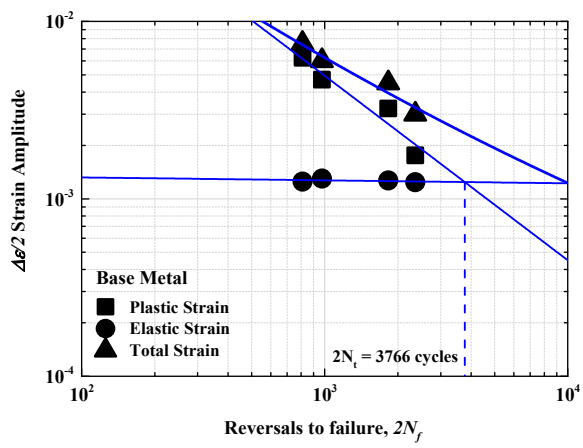

(a)

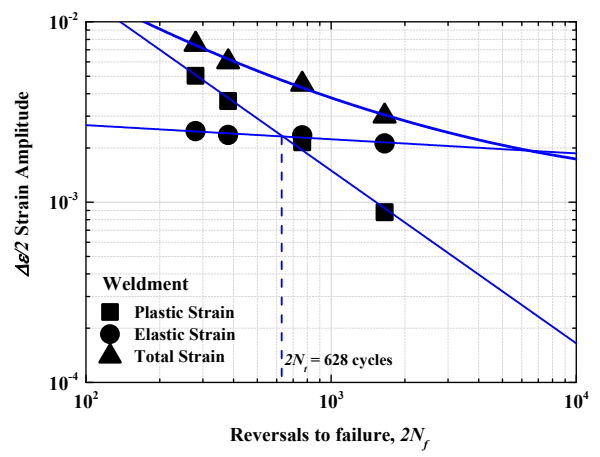

(b)

Figure 11. The Coffin-Manson curves of the Alloy 617: (a) base metal; (b) weldment specimens at $900{ }^{\circ} \mathrm{C}$ condition.

Table 1. The Coffin-Manson coefficients of Alloy 617 completed at $900{ }^{\circ} \mathrm{C}$ and a strain rate of $10^{-3} / \mathrm{s}$.

\begin{tabular}{cccccccc}
\hline Reference & $\varepsilon_{\mathbf{f}}{ }^{\prime}$ & $c$ & $\boldsymbol{\sigma}_{\mathbf{f}}{ }^{\prime}(\mathbf{M P a})$ & $\boldsymbol{b}$ & $\boldsymbol{E}(\mathbf{G P a})$ & $\boldsymbol{n}^{\prime}$ & $\boldsymbol{K}^{\prime}(\mathbf{M P a})$ \\
\hline Base Metal & 6.527 & -1.040 & 212.4 & -0.017 & 149 & -0.048 & 142.5 \\
Weldments & 1.120 & -0.958 & 572.2 & -0.078 & 149 & 0.087 & 613.9 \\
\hline
\end{tabular}

\subsection{Fracture Surface Characterization}

In order to investigate the failure location and mechanism of Alloy 617, the macro- and micro-structural analysis of selected specimens, were investigated using SEM along with an EDX facility, and OM. Figure 12 shows the comprehensive photographs and micrographs of the cracking and failure location of the Alloy 617 base metal and weldment specimens at $0.6 \%$ total strain range. In this investigation, we observed that the LCF crack initiation sites of Alloy 617 base metal and weldment fractured specimens illustrate a flat- and a shear-type crack in the free surface, and that LCF cracking occurred within the gauge section.
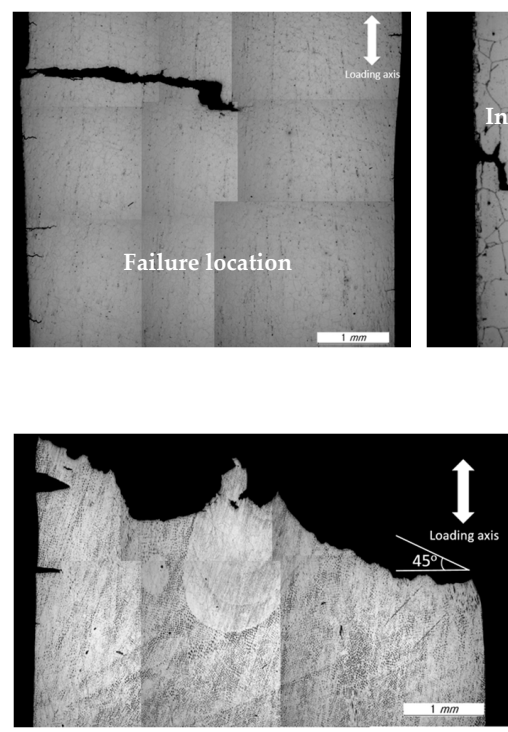

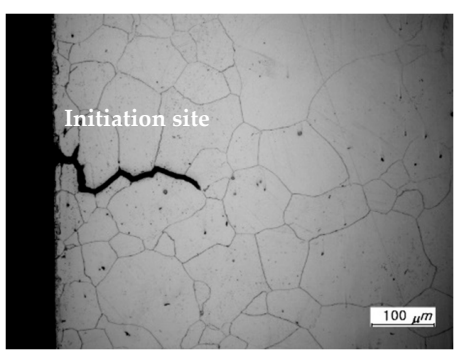

(a)

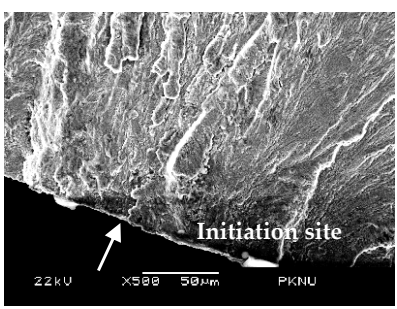

(b)
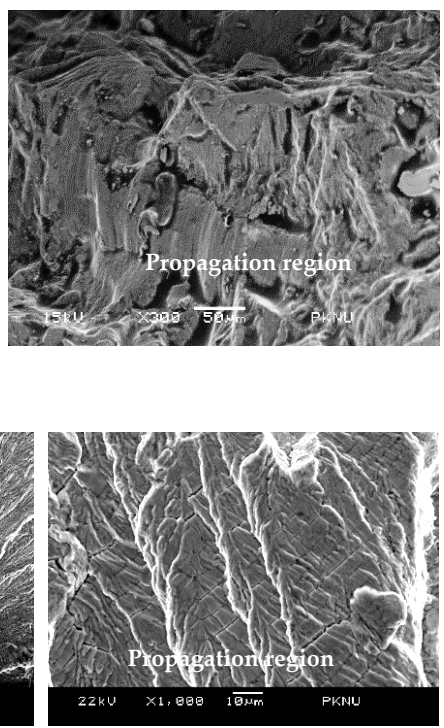

Figure 12. Scanning electron microscopy (SEM) and cross-view images of the selected specimens of Alloy 617 at $900{ }^{\circ} \mathrm{C}$ condition under LCF testing for (a) base metal; and (b) weldment specimen, total strain range of $0.6 \%$. (Left to right: Failure location, crack initiation, and crack propagation regions). 
From Figure 12a, it can be seen that the crack initiation site proceeded in the free surface through intergranular crack initiation resulting from oxidation of surface connected grain boundaries. It was found that the major role of reduction in the fatigue life of Alloy 617 base metal was probably generated from surface carbide oxidation. The LCF failure mechanism on the crack propagation as a result of the slip band containing extrusions and intrusions led to the propagation of a transgranular nature within the grain on the specimen surface, and finally at the critical stage, the primary crack is just about to fail. The LCF resistance of Alloy 617 is not affected by the intergranular creep damage mechanism. The strengthening of carbides creates a barrier to prevent intergranular creep crack by hindering grain boundary sliding and avoiding the concentration of stress. All of the base metal primary crack mechanism propagated in a transgranular nature with some quasi cleavage-facets and secondary cracks due to higher ductility of grain boundary carbides.

Figure $12 \mathrm{~b}$ demonstrates that the main crack for weldment specimens was presented in the weld metal region. However, since the weld metal has a fully austenitic and dendritic structure, these implications resulted in a strength and hardness much larger than the base, but lower than the HAZ due to grain boundary strengthening [2]. Especially in the fusion line, or migrated boundary, it is coupled with their bonding strength and interface connection which prevents the occurrence of cracking. In fact, the possible weakness of the weld metal as well as the presence of microstructural heterogeneity, including the residual stress effect due to the welding process, cause a strain localization in the weld region. Figure $12 \mathrm{~b}$ also shows the crack propagation of the weldments was followed by some quasi-cleavage like facets with striations due to the higher strength and lower ductility aside from the base metal. The formation of quasi-cleavage facets may be induced from the high stress concentration in the slip planes, thus, generating some cracks through the grains. We found that the crack initiation of the weldments emerged from a multi-site on the specimen surface, and was oriented about 45 or 135 degrees according to the loading direction due to the maximum shear stress.

Figure 13 shows the failure mechanism of the weldment specimens occurred due to the slip band process on the free surface, leading to the formation of a micro-crack within the grain on the specimen surface, and finally at the critical stage, coalescence of the micro-cracks develop into the macro-crack and the crack is propagated in transgranular nature across the dendritic structure. Again, as is seen from Figure 12, the fatigue striations on the weldment specimens are more obvious than on the base metal. The occurrence of fatigue striations was due to a repeated plastic blunting sharpening process arising from the slip of dislocations in the plastic zone of the fatigue crack tip [12]. However, the weldments could easily form fatigue striations and undergo quasi-cleavage facets due to their higher stress-strain interaction and being more brittle than that of the base metal [13].



Figure 13. Typical optical microscopy (OM) images of the Alloy 617 weldment specimen tested at $900{ }^{\circ} \mathrm{C}$, total strain range of $1.2 \%$ showing the LCF failure mechanism propagated across the dendritic structure.

Figure 14 shows typical micrographs of the Alloy 617 base metal crack initiation site. It is interesting to note that under higher total strain ranges, the reduction in fatigue life of the base metal 
is more clearly acquired, partly from homogenization of the slip process and an increase in plastic strain generated in the cycle, evidenced by several micro-cracks on the surface. At higher plastic deformation, this may induce a weak stress response because of more secondary cracks occurring in the grain boundary. In Figure 14 also indicates the LCF failures are often attended by intergranular crack initiation resulting from oxidation of surface connected grain boundaries.

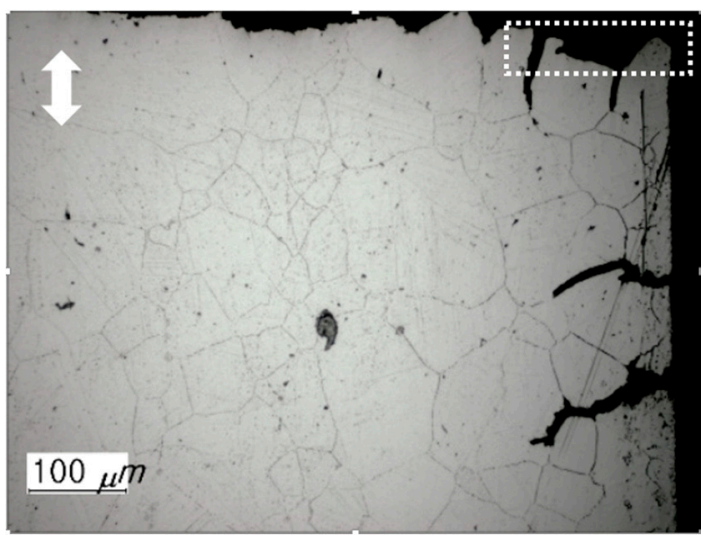

(a)

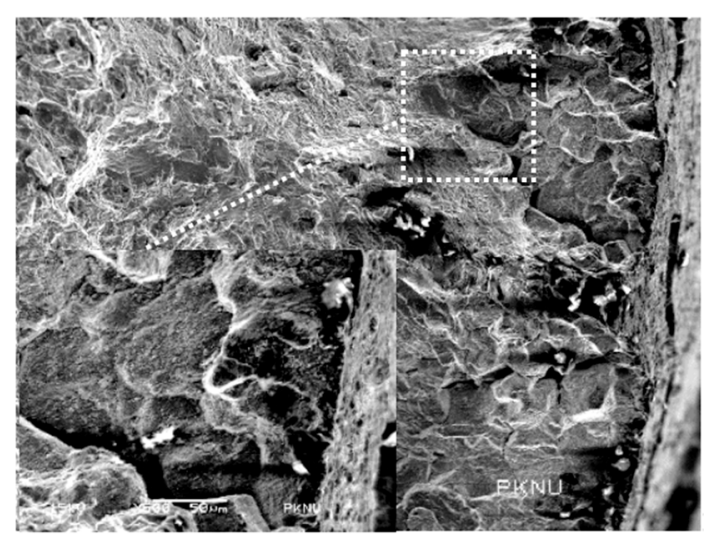

(b)

Figure 14. Typical micrographs of the Alloy 617 base metal tested at $900{ }^{\circ} \mathrm{C}$, total strain range of $1.2 \%$ shows critical damage induced by large plastic deformation, (a) micro-cracks on the surface; and (b) intergranular crack initiation due to the oxidation process.

The coarse carbide precipitations, $\mathrm{Cr}$-rich $\mathrm{M}_{23} \mathrm{C}_{6}$, evolved mainly on the grain boundaries. From in Figure 15, EDX analysis shows the carbide precipitations from $\mathrm{Cr}$ metallic particles. The primary carbides known as, $\mathrm{M}_{6} \mathrm{C}$, with large precipitations were formed in the body of the grain structure. Also, the secondary carbides $\left(\mathrm{M}_{23} \mathrm{C}_{6}\right)$ were found at the grain boundary. These carbide precipitations exist from chromium activities maintaining oxide formation on the surface.
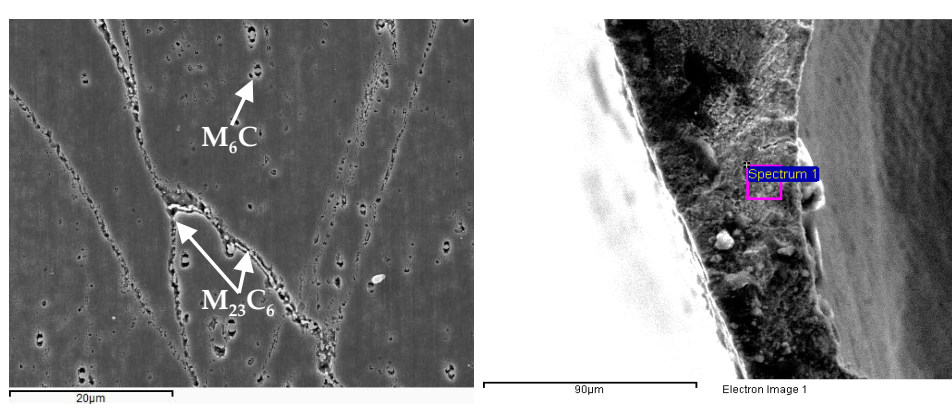

\begin{tabular}{ccc}
\hline Element & Weight $\%$ & Atomic\% \\
\hline Ca K & 0.42 & 0.38 \\
Ti K & 0.32 & 0.24 \\
Cr K & 12.67 & 8.83 \\
Co K & 6.04 & 3.71 \\
Ni K & 56.15 & 34.67 \\
Mo L & 1.65 & 0.62 \\
O K & 22.75 & 51.54 \\
\hline
\end{tabular}

Figure 15. SEM and energy dispersive X-ray (EDX) examination of the Alloy 617 weldment specimen tested at $900{ }^{\circ} \mathrm{C}$, total strain range of $0.6 \%$ demonstrating precipitations formed on the grain boundaries.

On the outer surface, a $\mathrm{Cr}$-rich (mainly $\mathrm{Cr}_{2} \mathrm{O}_{3}$ ) oxide layer was formed owing to $\mathrm{Cr}$ diffusion from the matrix. Surface oxidation is evident owing to prolonged exposure time at very high temperature. In a previous work [15], it was stated that internal sub layers consisting of (Al-rich and carbides) were formed by the diffusion of oxygen through the surface oxide and matrix just beneath the $\mathrm{Cr}_{2} \mathrm{O}_{3}$ layer. The $\mathrm{Cr}_{2} \mathrm{O}_{3}$ layer is of the anion diffusion type, which prevents further diffusion of oxygen. We believe that transgranular crack propagation is associated with the excellent oxidation resistance of the Alloy 617, although, the intergranular cracking is initiated and developed by incorporation of oxidation of the surface connected grain boundaries together with environmentally generated mixed mode propagation. 
At the end, the final stage where the material no longer holds the applied stress, namely the failure region, both base metal and weldment specimens exhibit shear, or dimple features. In Figure 16, SEM and EDX spectrum examination show a failure region of the weldments. However, the weldment specimens showed less dimple features due to lower ductility properties compared to the base metal. Furthermore, the EDX examinations show that the dimple features were observed with the occurrence of dominating metallic precipitations by $\mathrm{Cr}, \mathrm{Mo}, \mathrm{Co}$, and $\mathrm{Ni}$.

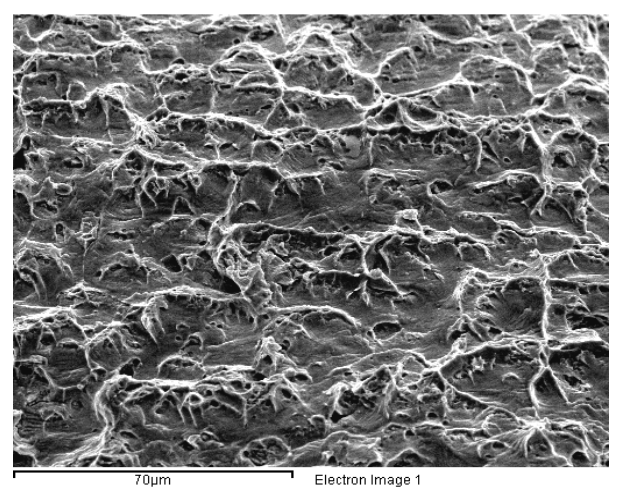

\begin{tabular}{ccc}
\hline Element & Weight\% & Atomic\% \\
\hline Al K & 1.40 & 3.03 \\
Si K & 0.68 & 1.40 \\
Ti K & 0.80 & 0.97 \\
Cr K & 23.65 & 26.48 \\
Fe K & 0.59 & 0.62 \\
Co K & 11.05 & 10.92 \\
Ni K & 49.51 & 49.11 \\
Mo L & 12.32 & 7.48 \\
\hline
\end{tabular}

Figure 16. SEM and EDX examination of the Alloy 617 weldment specimen tested at $900{ }^{\circ} \mathrm{C}$, total strain range of $0.6 \%$ refers to the final failure region with some dimples features together with its composition.

\section{Conclusions}

The LCF tests of Alloy 617 base metal and weldments were conducted at a high temperature of $900{ }^{\circ} \mathrm{C}$ under four different total strain ranges in air. Under all the testing conditions, the weldment specimens showed lower fatigue lives compared with the base metal, and also the fatigue lives both of base metal and weldment specimens were decreased on increasing the total strain range. The overall cyclic stress response curve of the weldment specimens was higher than that of the base metal. The weldment specimens exhibited a cyclic hardening behavior during cyclic loadings, whereas the base metal experienced a cyclic softening induced by solute drag creep as a function of total strain range. In addition, the Coffin-Manson relationship analysis revealed that the $c$ slope value is equal to -1.04 and -0.96 of the Alloy 617 base metal and weldment specimens, respectively.

The failure mechanism for Alloy 617 base metal occurring in the intergranular cracking is initiated by incorporation of oxidation of surface connected grain boundaries, and propagated in a transgranular nature., The main crack for weldment specimens presented itself in the weld metal region, whereas crack initiation emerged from multi-sites and was also oriented at about 45 or 135 degrees according to the loading direction. The main crack for weldment specimens occurred of a transgranular nature across the dendritic structure while the propagation area with clear striations was also observed.

Acknowledgments: The authors would like to recognize KAERI, and acknowledge that this research was supported by Nuclear Research \& Development Program through the National Research Foundation of Korea (NRF) funded by the Ministry of Science, ICT \& Future Planning (NRF-2016M2A8A2902895).

Author Contributions: Seon Jin Kim formulated this research with cooperation from Woo Gon Kim and Eung Seon Kim. Rando Tungga Dewa performed the experiment works, with the help of Seon Jin Kim, interpreted the results and prepared the manuscript. All co-authors contributed to the manuscript proof and submissions.

Conflicts of Interest: The authors declare no conflict of interest.

\section{References}

1. Dewa, R.T.; Kim, S.J.; Kim, W.G.; Kim, E.S. Low cycle fatigue behaviors of Alloy 617 (INCONEL 617) weldments for high temperature applications. Metals 2016, 6, 100. [CrossRef]

2. Kim, S.J.; Dewa, R.T.; Kim, W.G.; Kim, M.H. Cyclic stress response and fracture behaviors of Alloy 617 base metal and weldments under LCF loading. Adv. Mater. Sci. Eng. 2015, 2015. [CrossRef] 
3. Lee, H.Y.; Kim, Y.W.; Song, K.N. Preliminary application of the draft code case for alloy 617 for a high temperature component. J. Mech. Sci. Technol. 2008, 22, 856-863. [CrossRef]

4. Lee, G.G.; Jung, S.; Park, J.Y.; Kim, W.G.; Hong, S.D.; Kim, Y.W. Microstructural investigation of Alloy 617 creep-ruptured at high temperature in a helium environment. J. Mater. Sci. Technol. 2013, 29, 1177-1183. [CrossRef]

5. Wright, J.K.; Carroll, L.J.; Cabet, C.; Lillo, T.M.; Benz, J.K.; Simpson, J.A.; Lloyd, W.R.; Chapman, J.A.; Wright, R.N. Characterization of elevated temperature properties of heat exchanger and steam generator alloys. Nucl. Eng. Des. 2012, 251, 252-260. [CrossRef]

6. Wright, J.K.; Carroll, L.J.; Wright, R.N. Creep and creep-fatigue of Alloy 617 weldments. Available online: http:/ /www.osti.gov/scitech/biblio/1168621 (accessed on 26 July 2016).

7. Totemeier, T.C.; Tian, H.; Clark, D.E.; Simpson, J.A. Microstructure and strength characteristics of Alloy 617 welds. Available online: https://inldigitallibrary.inl.gov/sti/3310959.pdf (accessed on 26 July 2016).

8. Wright, J.K.; Carroll, L.J.; Simpson, J.A.; Wright, R.N. Low cycle fatigue of Alloy 617 at $850{ }^{\circ} \mathrm{C}$ and $950{ }^{\circ} \mathrm{C}$. J. Eng. Mater. Technol. 2013, 135, 1-8. [CrossRef]

9. Rao, K.B.S.; Meurer, H.P.; Schuster, H. Creep-fatigue interaction of lnconel 617 at $950{ }^{\circ} \mathrm{C}$ in simulated nuclear reactor helium. Mater. Sci. Eng. A 1988, 104, 37-51. [CrossRef]

10. Ren, W.; Swindeman, R. A review on current status of Alloys 617 and 230 for Gen IV nuclear reactor internals and heat exchangers. J. Press. Vessel Technol. 2009, 131. [CrossRef]

11. Rahman, M.S.; Priyadarshan, G.; Raja, K.S.; Nesbitt, C.; Misra, M. Characterization of high temperature deformation behavior of INCONEL 617. Mech. Mater. 2009, 41, 261-270. [CrossRef]

12. Tian, D.D.; Liu, X.S.; He, G.Q.; Shen, Y.; Lv, S.Q.; Wang, Q.G. Low cycle fatigue behavior of casting A319 alloy under two different aging conditions. Mater. Sci. Eng. A 2016, 654, 60-68. [CrossRef]

13. Zhang, Q.; Zhang, J.; Zhao, P.; Huang, Y.; Yu, Z.; Fang, X. Low-cycle fatigue behaviors of a new type of $10 \%$ $\mathrm{Cr}$ martensitic steel and welded joint with Ni-based weld metal. Int. J. Fatigue 2016, 88, 78-87. [CrossRef]

14. Jang, C.; Lee, D.; Kim, D. Oxidation behaviour of an Alloy 617 in very high-temperature air and helium environments. Int. J. Press. Vessels Pip. 2008, 85, 368-377. [CrossRef]

15. Kim, W.G.; Park, J.Y.; Lee, G.G.; Hong, S.D.; Kim, Y.W. Temperature effect on the creep behavior of alloy 617 in air and helium environments. Nucl. Eng. Des. 2014, 271, 291-300. [CrossRef]

(C) 2016 by the authors; licensee MDPI, Basel, Switzerland. This article is an open access article distributed under the terms and conditions of the Creative Commons Attribution (CC-BY) license (http://creativecommons.org/licenses/by/4.0/). 